\title{
CXCR4/CXCR7/CXCL12 axis promotes an invasive phenotype in medullary thyroid carcinoma
}

\author{
Thomas A Werner ${ }^{1}$, Christina M Forster ${ }^{1}$, Levent Dizdar ${ }^{1}$, Pablo E Verde ${ }^{2}$, Katharina Raba ${ }^{3}$, Matthias Schott ${ }^{4}$, \\ Wolfram T Knoefel ${ }^{1}$ and Andreas Krieg*,1 \\ ${ }^{1}$ Department of Surgery (A), Heinrich-Heine-University and University Hospital Duesseldorf, Moorenstr. 5, Duesseldorf 40225, \\ Germany; ${ }^{2}$ Coordination Centre for Clinical Trials, Heinrich-Heine-University and University Hospital Duesseldorf, Moorenstr. 5, \\ Duesseldorf 40225, Germany; ${ }^{3}$ Institute for Transplantation Diagnostics and Cell Therapeutics, Heinrich-Heine-University and \\ University Hospital Duesseldorf, Moorenstr. 5, Duesseldorf, 40225, Germany and ${ }^{4}$ Division for Specific Endocrinology, Heinrich- \\ Heine-University and University Hospital Duesseldorf, Moorenstr. 5, Duesseldorf 40225, Germany
}

Background: Medullary thyroid carcinoma (MTC) is a rare and challenging endocrine malignancy. Once spread, the therapeutic options are limited and the outcome poor. For these patients, the identification of new druggable biological markers is of great importance. Here, we investigated the prognostic and biological role of the C-X-C chemokine receptors type 4 and 7 (CXCR4/7) in MTC.

Methods: Eighty-six MTC and corresponding non-neoplastic thyroid specimens were immunohistochemically stained for CXCR4/ 7 using tissue microarray technology and expression levels correlated with clinicopathological variables. Medullary thyroid carcinoma cell line TT was treated with recombinant human SDF1 $\alpha / C X C L 12$ (rh-SDF1 $\alpha$ ) and CXCR4 antagonists AMD3100 and WZ811. Changes in cell cycle activation, tumour cell invasiveness as well as changes in mRNA expression levels of genes associated with epithelial-mesenchymal transition (EMT) were investigated.

Results: High CXCR4 expression was associated with large tumour size and metastatic disease. CXCR4 antagonists significantly reduced tumour cell invasiveness, while the treatment with rh-SDF1 $\alpha$ stimulated invasive growth, caused cell cycle activation and induced EMT.

Conclusions: The CXCR4/CXCR7/CXCL12 axis plays an important role in MTC. We provide first evidence that the chemokine receptors might serve as potential therapeutic targets in patients with advanced MTC and offer new valuable insight into the underlying molecular machinery of metastatic MTC.

Medullary thyroid carcinoma (MTC) is a rare endocrine malignancy, which accounts for $\sim 5 \%$ of all thyroid carcinomas. It derives itself from the calcitonin-secreting, parafollicular $\mathrm{C}$ cells of the thyroid gland (Ball, 2009). Unlike other thyroid malignancies, MTC shows a strong hereditary predisposition. Approximately $25 \%$ of all cases are associated with an activating germline mutation of the REarranged during Transfection (RET) proto- oncogene (Donis-Keller et al, 1993; Takahashi, 1995). RET encodes for a receptor tyrosine kinase that influences cell death and differentiation as well as migration and cell cycle progression. Interestingly, RET gain-of-function mutations are also present in the majority of sporadic MTCs (Hu et al, 2014).

Hereditary MTCs are associated with multiple endocrine neoplasia syndromes type $2 \mathrm{~A}$ and $\mathrm{B}(\mathrm{MEN} 2 \mathrm{~A} / \mathrm{B})$. While both

*Correspondence: Dr A Krieg; E-mail: andreas.krieg@med.uni-duesseldorf.de

Received 24 April 2017; revised 13 September 2017; accepted 14 September 2017; published online 7 November 2017

(C) 2017 Cancer Research UK. All rights reserved 0007-0920/17 
syndromes harbour different extrathyroidal endocrine manifestations such as pheochromocytoma or primary hyperparathyroidism, MTC is the dominant clinical sign, present in almost all the patients (Eng et al, 1996; Leboulleux et al, 2004; Wells et al, 2013).

To date, depending on the preoperative staging and the serum level of calcitonin radical thyroidectomy with or without lymphadenectomy remains the only curative treatment option for MTC patients (American Thyroid Association Guidelines Task Force et al, 2009; Dralle et al, 2013). However, the majority of patients harbour regional or distant metastases at the time of diagnosis, rendering surgery alone insufficient. Hence, the development of new systemic therapeutic regimes based on the everimproving understanding of MTC oncogenesis has been in the focus of clinical researchers worldwide (Tuttle et al, 2010). The common alteration of the RET proto-oncogene in sporadic as well as in hereditary MTC has placed the emphasis on tyrosine kinase inhibitors (TKI). This led to the inclusion of TKI as standard of care for patients with advanced MTC. However, the small molecule TKI could thus far not live up to their expectations (Haddad, 2013; Strosberg, 2013). Once the tumour has spread the 10-year survival rate remains poor with only 21\% (American Thyroid Association Guidelines Task Force et al, 2009).

Metastatic spread is the most relevant prognostic determinant in MTC. Although different pathways like the activation of the RET proto-oncogene and the overexpression of epidermal as well as vascular endothelial growth factor receptor have been implicated with metastatic MTC (Links et al, 2015), the specific cellular factors determining tumour cell invasion and subsequent metastasis are thus far uncertain. However, to develop new treatment strategies for this subset of patients a better understanding of the molecular pathways involved appears mandatory. The forming of metastases is a closely coordinated and organ-specific procedure, which offers many similarities to that of leukocyte trafficking, a procedure closely monitored by chemokines and their respective receptors (Nicolson, 1993; Müller et al, 2001). In this regard, C-X-C chemokine receptors type 4 and 7 (CXCR4, CXCR7) as well as its ligand stromal cell-derived factor 1 alpha (SDF1 1 ), also known as CXCL12, have been implicated in various types of carcinomas (Sun et al, 2010). The G protein-coupled chemokine receptor CXCR4 is expressed in a wide range of tissues during embryogenesis, including the immune and central nervous systems. It plays an important role during angiogenesis and is mandatory for haematopoietic progenitors (Scala, 2015). The outstanding role of CXCR4 and its ligand is further underlined by the fact that its loss of function causes embryologic death. This circumstance is rarely observed for other chemokine or $G$ protein-coupled receptors in general (Tachibana et al, 1998; Rosenkilde et al, 2004). Differential expression of CXCR4 is further involved in regulating stem cell trafficking, cerebellar development and immune response. While mostly absent under physiological conditions in many adult tissues, CXCR4 is overexpressed in a variety of human carcinomas (Balkwill, 2004; Pozzobon et al, 2016). In this regard, regional hypoxia in the tumour mass causes the release of Hypoxia-inducible factor 1 (HIF-1) into the tumour microenvironment, which in turn facilitates the upregulation of CXCR4, prompting tumour cell survival through metastatic spread (Scala, 2015).

SDF $1 \alpha$ is a broadly expressed chemokine, which functions as a potent chemoattractant for CXCR4-expressing cells. It is highly expressed in the most common metastatic organs like lymph nodes, liver, lung and bone (Secchiero et al, 2000; Roland et al, 2003; Wright et al, 2005). Different studies have shown that CXCR4-positive cells follow a chemokine gradient to SDF1 $\alpha$ expressing tissues to form distant metastases. Besides chemotaxis, binding of SDF1 $\alpha$ to CXCR4 causes the activation of intracellular pathways, which are associated with epithelial-mesenchymal transition (EMT), proliferation and survival (Sun et al, 2010).
In addition to CXCR4, SDF1 $\alpha$ also binds to CXCR7, a chemokine receptor found to be significantly upregulated in different types of epithelial tumours (Gebauer et al, 2011; Schrevel et al, 2012; Chen et al, 2015). It has been demonstrated that CXCR7 promotes tumour cell survival by inhibiting apoptosis and facilitates colony formation through increased focal adhesion properties (Burns et al, 2006). Other studies suggested that CXCR7 functions as a co-receptor to CXCR4, thus enhancing SDF1 $\alpha$ mediated G protein signalling (Levoye et al, 2009; Sun et al, 2010).

The aim of our study was to investigate the stage-dependent expression of CXCR4 and CXCR7 in MTC and to elucidate the functional implications of the CXCR4/CXCR7/CXCL12 axis in MTC.

MATERIALS AND METHODS

Patient selection and clinicopathological data. All patients who underwent all types of thyroidectomy for histologically confirmed MTC, irrespective of tumour stage and microscopic resection margin, at the Department of Surgery (A), University Hospital Duesseldorf between 1986 and 2003 were retrospectively reviewed and included in this study. Our exclusion criteria comprised incomplete pathological report, missing clinical data, incomplete resection or insufficient tissue material for subsequent analysis. Follow-up data were obtained from our prospectively maintained clinical database. Overall survival was defined as the time in months from the date of surgery until death of any cause or until the last follow-up at which survivors were censored. Patients who died within the first 30 days upon surgery were not included in the survival analysis. Clinical data including sex, age at first diagnosis, serum calcitonin levels prior to surgery, genetic profiles regarding sporadic and inherited MTC as well as the initial tumour stage were retrospectively reviewed. During the time of the study different calcitonin assays had been used. Here we focussed on the numeric calcitonin basal blood levels prior to surgery irrespective of the assay method employed. Medullary thyroid carcinomas were staged according to the 8th edition of the UICC classification (Brierley et al, 2016).

The study was carried out in accordance to Good Clinical Practice, the Declaration of Helsinki and local rules as well as regulations of the country. Strict anonymity of all patients' data were established and maintained throughout the study. An approval from the institutional ethics committee of the Medical Faculty, Heinrich Heine University Duesseldorf was obtained (reference number: 3821).

Tissue microarray and immunohistochemistry. All formalinfixed paraffin-embedded tissue samples were provided from the Institute of Pathology, University Hospital Duesseldorf. The construction of the tissue microarrays, immunohistochemistry and analysis of protein expression using the immunoreactivity score (IRS) reported by Remmele (Remmele et al, 1986) were performed as described previously (Werner et al, 2016). The staining intensity of the different samples was reviewed by two independent investigators (TW and CF) in a blinded manner.

For immunohistochemical staining the following primary antibodies were used: mouse monoclonal anti-CXCR4 (1:100 dilution; Abcam, Cambridge, UK), rabbit polyclonal anti-CXCR7 ( $1: 200$ dilution; GeneTex, Irvine, CA, USA).

Isotype controls were performed using mouse IgG1k (MOPC21; 1:50 dilution; Abcam) or rabbit immunoglobulin fraction (Code X0903; 1:1000 dilution; Dako, Glostrup, Denmark). CXCR4-expressing tonsil tissue and CXCR7-expressing pancreatic adenocarcinoma served as positive controls. The prognostic power of CXCR4 and CXCR7 was assessed according to the REporting 
recommendations for tumour MARKer prognostic studies (REMARK) (McShane et al, 2005).

Cell culture and reagents. The human MTC cell line TT was purchased from the American Type Culture Collection (ATCC, Middlesex, UK; CRL-1803). The cell line was cultivated in F-12K medium (Gibco Thermo Fisher, Waltham, MA, USA), supplemented with $10 \%$ foetal bovine serum. Cell line authenticity was confirmed as described previously (Krieg et al, 2014). Recombinant human (rh) SDF1 $\alpha$ was purchased from PeproTech (Rocky Hill, NJ, USA). Specific CXCR4 antagonist plerixafor (AMD3100) and WZ811 were obtained from Selleck Chemicals (Houston, TX, USA).

Invasion assay. TT cells were treated with different concentrations of rh-SDF1 $\alpha$, AMD3100, WZ811 or vehicle control at equimolar concentrations for $24 \mathrm{~h}$ in serum-starved culture medium. Afterwards, cells were harvested and seeded on BD Matrigel invasion chambers (BD Biosciences, Heidelberg, Germany) at a density of $5 \times 10^{4}$ cells $\mathrm{ml}^{-1}$ in $\mathrm{F}-12 \mathrm{~K}$ medium supplemented with $0.25 \%$ bovine serum albumin. Conditioned Dulbecco's Modified Eagle Medium from CXCL12-expressing NIH 3T3 fibroblasts (Burger and Kipps, 2006; Lagergren et al, 2007) was used as chemoattractant and added to the lower chamber. After $24 \mathrm{~h}$ of incubation, cells were fixed with methanol and stained with 4',6-diamidin-2phenylindol (DAPI; $200 \mathrm{ng} \mathrm{ml}^{-1}$ ). 4',6-diamidin-2-phenylindolpositive cells were counted in five visual fields of three separate membranes under a fluorescence microscope at $\times 200$ magnification (Zeiss Axioplan 2, Carl Zeiss, Göttingen, Germany).

FACS cell cycle analysis. TT cells were treated with different concentrations of rh-SDF1 $\alpha$, AMD3100, WZ811 or vehicle control at equimolar concentrations for $48 \mathrm{~h}$. For subsequent cell cycle analysis, TT cells were harvested and washed in cold PBS and resuspended in $80 \%$ ethanol. After incubation for $2 \mathrm{~h}$, cells were washed in PBS and incubated with RNAse A $\left(100 \mu \mathrm{g} \mathrm{ml}^{-1}\right)$ and propidium iodide (PI; $50 \mu \mathrm{g} \mathrm{ml}^{-1}$ ) for $30 \mathrm{~min}$ at $37^{\circ} \mathrm{C}$. Finally, cells were analysed by fluorescence-activated cell sorting (FACS) using a BD FACSCanto II (BD Biosciences, San Jose, CA, USA).

BrdU proliferation assay. Cell proliferation was assessed in 96well culture plates with cells plated at a concentration of $4 \times 10^{3}$ per well under serum-starved culture conditions. After $24 \mathrm{~h}$ cells were incubated for $48 \mathrm{~h}$ with rh-SDF1 $\alpha$, AMD3100, WZ811 or vehicle control at equimolar concentrations. To assess cell proliferation the Cell Proliferation ELISA, BrdU assay (Roche Applied Science, Mannheim, Germany) was performed at an absorbance at $370 \mathrm{~nm}$ according to the manufacturer's protocol. All assays were analysed using an Infinite 200 microplate reader (Tecan Group Ltd., Crailsheim, Germany).

Western blot analysis. For protein isolation, cells were lysed in ice-cold RIPA buffer. Total protein concentrations were measured using a BioPhotometer (Eppendorf, Hamburg, Germany). Proteins were separated using SDS-polyacrylamid gel electrophoresis and transferred onto a nitrocellulose membrane for antibody-detection. Membranes were incubated overnight using the following primary antibodies: mouse monoclonal anti-CXCR4 (1:100 dilution; Abcam), rabbit polyclonal anti-CXCR7 (1:200 dilution; GeneTex).

Immunocytochemistry. Cells were fixed with ice-cold methanol and incubated with $0.5 \%$ Triton. Unspecific epitops were blocked using 20\% AB serum. Next, cells were incubated with their respective primary antibody or isotype control (mouse monoclonal anti-CXCR4, 1:250 dilution; Abcam; rabbit polyclonal antiCXCR7, 1:500 dilution; GeneTex; mouse IgG1k (MOPC-21); $2 \mu \mathrm{g} \mathrm{ml}^{-1}$; Abcam; rabbit immunoglobulin fraction (Code X0903) $2 \mu \mathrm{g} \mathrm{ml}^{-1}$; Dako). After $45 \mathrm{~min}$ of incubation, cells were washed and treated with either anti-mouse- or anti-rabbit-Alexa Fluor 488 (10 $\mu \mathrm{g} \mathrm{ml}^{-1}$; Thermo Fisher). Nuclear staining was achieved using
DAPI (200 $\left.\mathrm{ng} \mathrm{ml}^{-1}\right)$. After fixation with $1 \%$ PFA, the cells were visualised using a fluorescence microscope at $\times 400$ magnification (Zeiss Axioplan 2, Carl Zeiss).

RT-PCR. Total RNA was extracted from cells using the RNeasy Mini Kit according to the manufacturer's protocol (Qiagen, Hilden, Germany). Complementary DNA (cDNA) was synthesised from $2 \mu \mathrm{g}$ of total RNA using the qScript cDNA Synthesis Kit (QuantaBio, Beverly, MA, USA) following the manufacturer's instructions. The cDNA was then adjusted to a final concentration of $1 \mathrm{ng} \mathrm{l}^{-1}$. For the subsequent quantitative real-time-PCR (qRT-PCR), $2 \mu \mathrm{l}$ of cDNA template were mixed with $10 \mu \mathrm{l}$ PerfeCTa Fast Mix II (QuantaBio), $0.2 \mu \mathrm{l}$ probe (100 nm; Roche) and $0.2 \mu \mathrm{l}$ of forward and reverse primer (200 nM each). All templates were run as triplicates. Glyceraldehyde-3-phosphate dehydrogenase served as internal reference gene. The primers used are listed in Supplementary Table 1. All experiments were performed on the DyadDisciple Chromo 4 (BioRad) using the following set-up: $95^{\circ} \mathrm{C}$ for $2 \mathrm{~min}$, followed by 40 cycles of denaturation at $95^{\circ} \mathrm{C}$ for $10 \mathrm{~s}$ and annealing and extension at $60{ }^{\circ} \mathrm{C}$ for $30 \mathrm{~s}$. Gene expression was quantified according to the $2^{-\triangle \triangle \mathrm{CT}}$ method (Livak and Schmittgen, 2001).

Statistical analysis. Correlations between the IRS of CXCR4 or CXCR7 and the respective clinicopathological parameters were evaluated by logistic regression analyses and the non-parametric Spearman correlation. Changes in chemokine receptor expression between groups were assessed using the non-parametric MannWhitney $U$ test or the Wilcoxon matched-pairs signed rank test as indicated. In addition, the data were categorised according to the respective mean IRS and analysed by the Fisher's exact test. Univariate survival analyses were performed by the log-rank (Mantel-Cox) test. Cox regression analyses were used to estimate hazard ratios (HR) with 95\% confidence intervals (CI) for multivariate analyses including all variables. Moreover, a search for the best model was conducted using a stepwise variable selection procedure based on the Akaike Information Criterion (AIC). Cell culture experiments were repeated at least three times and evaluated for statistical significance using the non-parametric Mann-Whitney $U$ test.

Statistical analyses were computed using GraphPad Prism (Version 6, GraphPad Software, San Diego, CA, USA) and the Statistical Software R version 3.1.0. A $P$-value $<0.05$ was considered statistical significant.

\section{RESULTS}

Patients and outcome. Overall 86 patients were included in our study. The patients' characteristics are illustrated in Table 1 . The median overall survival in our cohort of patients was 170 months (range 5-287) with a median follow-up of 191 months (range 5-287) based on the reverse Kaplan-Meier procedure. The last follow-up was performed in January 2013. During this period of time 19 patients died. Owing to loss of follow-up, 11 patients were unavailable for subsequent survival analysis. The calcitonin basal blood levels prior to surgery were available for 67 patients, with a median of $304 \mathrm{pg} \mathrm{ml}^{-1}$. The genesis of the malignancy, whether sporadic or inherited, was known for the majority of patients. Only for eight patients the genetic profile was unavailable. While there were differences in surgical treatment between the patients, owed to the given recommendations at the respective time, the great majority of patients underwent radical, total thyroidectomy.

Expression of CXCR4 correlates with advanced tumour stage and metastatic phenotype. First, we compared the IRS of the two chemokine receptors in MTC samples and corresponding nonneoplastic thyroid tissues, lymph node as well as distant metastases. Whereas primary tumour samples and corresponding metastases 
Table 1. Patient characteristics $(n=86)$

\begin{tabular}{|c|c|}
\hline Variables & No. of patients (\%) \\
\hline Total & 86 \\
\hline \multicolumn{2}{|l|}{ Age } \\
\hline Median (range); years & $48(6-83)$ \\
\hline \multicolumn{2}{|l|}{ Gender } \\
\hline $\begin{array}{l}\text { Male } \\
\text { Female }\end{array}$ & $\begin{array}{l}42(49) \\
44(51)\end{array}$ \\
\hline \multicolumn{2}{|l|}{ Genetic } \\
\hline $\begin{array}{l}\text { Sporadic } \\
\text { MEN2A } \\
\text { Unknown }\end{array}$ & $\begin{array}{c}40(47) \\
38(44) \\
8(9)\end{array}$ \\
\hline \multicolumn{2}{|c|}{ Basal calcitonin levels prior to surgery } \\
\hline $\begin{array}{l}<12 \mathrm{pg} \mathrm{ml}^{-1} \\
>12 \mathrm{pg} \mathrm{ml}^{-1} \\
\text { Unknown }\end{array}$ & $\begin{array}{c}9(10) \\
58(68) \\
19(22)\end{array}$ \\
\hline \multicolumn{2}{|l|}{ Type of surgery } \\
\hline $\begin{array}{l}\text { Hemithyroidectomy } \\
\text { with unilateral ND } \\
\text { Subtotal thyroidectomy } \\
\text { with bilateral ND } \\
\text { Total thyroidectomy } \\
\text { with unilateral ND } \\
\text { with bilateral ND }\end{array}$ & $\begin{aligned} & 11(13) \\
3 & (3) \\
7 & (8) \\
2 & (2) \\
16 & (19) \\
16 & (19) \\
31 & (36)\end{aligned}$ \\
\hline \multicolumn{2}{|l|}{ Side affected } \\
\hline $\begin{array}{l}\text { Unilateral } \\
\text { Bilateral }\end{array}$ & $\begin{array}{l}70(81) \\
16(19)\end{array}$ \\
\hline \multicolumn{2}{|l|}{ Tumour stage } \\
\hline $\begin{array}{l}\mathrm{T} 1 / 2 \\
\mathrm{~T} 3 / 4\end{array}$ & $\begin{array}{l}67(78) \\
19(22)\end{array}$ \\
\hline \multicolumn{2}{|c|}{ Lymph node metastasis } \\
\hline $\begin{array}{l}\mathrm{N} \text { negative } \\
\mathrm{N} \text { positive }\end{array}$ & $\begin{array}{l}43(50) \\
43(50)\end{array}$ \\
\hline \multicolumn{2}{|l|}{ Distant metastasis } \\
\hline $\begin{array}{l}\text { M0 } \\
\text { M1 }\end{array}$ & $\begin{array}{l}68(79) \\
18(21)\end{array}$ \\
\hline \multicolumn{2}{|l|}{ UICC stage } \\
\hline $\begin{array}{l}\text { UICC I/II } \\
\text { UICC III/IV }\end{array}$ & $\begin{array}{l}41(48) \\
45(52)\end{array}$ \\
\hline
\end{tabular}

stained strongly positive for CXCR4, normal thyroid tissue samples exhibited predominantly no expression of CXCR4 $(P<0.001$; Figure $1 \mathrm{~A}$ and $\mathrm{B})$. In contrast, almost all tissue specimens stained negatively for CXCR7 in both tumour and corresponding unaffected tissue cores. Only one primary tumour exhibited a strong expression for CXCR7, whereas three lymph node metastases demonstrated a weak expression for CXCR7 (data not shown).

To further investigate a possible association between different clinicopathological parameters and CXCR4 expression, the IRS for CXCR4 was compared across groups of different clinicopathological variables. Interestingly, we found a strong association between high CXCR4 expression and large tumour size (T1/2 vs T3/4: $P<0.01$; Figure $2 \mathrm{~A}$ ) as well as advanced tumour stages (UICC I/II vs UICC III/IV: $P<0.001$; Figure $2 \mathrm{~B}$ ). In addition, patients with lymph node or distant metastases exhibited a significantly higher expression of CXCR4 in their primary tumour cores when compared to patients' samples without metastases ( $\mathrm{N}$ neg. vs $\mathrm{N}$ pos.: $P<0.001$; M0 vs M1: $P<0.01$; Figure $2 \mathrm{C}$ and $\mathrm{D})$. Of note, CXCR4 was also significantly higher expressed in the lymph node metastases than in the corresponding primary tumour $(P<0.001$; Figure 1B). Moreover, tumours from patients with a sporadic genesis of their disease and advanced age at the time of first diagnosis exhibited markedly higher expression levels of CXCR4 (sporadic vs MEN2A: $P<0.001$; Age $<$ median vs Age $\geqslant$ median: $P<0.05$; Figure $2 \mathrm{E}$ and $\mathrm{F}$ ). Using CXCR4 as a continuous variable, the logistic regression analysis further confirmed the strong correlation between increasing expression levels of CXCR4 and larger tumour diameter, reflected by high $\mathrm{T} 3 / 4$ stage ( $\mathrm{rs}=0.547$; 95\% CI: $0.373-0.683 ; P<0.001)$, and the presence of lymph node (rs $=0.563$; 95\% CI: 0.394-0.696; $P<0.001$ ) and distant metastases (rs $=0.354 ; 95 \%$ CI: $0.147-0.531 ; P<0.001$; Figure $2 \mathrm{G}$ ).

These findings were confirmed by categorising the CXCR4 expression into high (IRS $\geqslant$ median) and low (IRS $<$ median) and comparing the expression levels with regard to the different clinicopathological parameters by using the Fisher's exact test (Supplementary Table 2).

CXCR4 expression is a negative prognostic marker in MTC. To further explore a prognostic relevance of CXCR4 in MTC univariate survival analyses were performed. Accordingly, a high CXCR4 expression was strongly associated with a poor overall survival in MTC patients $(\mathrm{HR}=4.474 ; 95 \% \mathrm{CI}$ : 1.671-11.98; $P<0.001$; Table 2). In addition, other clinicopathological markers such as old age at first diagnosis, sporadic MTC, present lymph node or distant metastases and advanced T3/T4 tumour stages predicted poor prognosis (Table 2).

In the subsequent multivariate analysis including all variables, no clinicopathological parameter came up as an independent negative prognostic marker (Table 2). However, the implementation of a variable selection procedure based on the AIC identified the presence of distant metastases at the time of first diagnosis to be an independent prognostic factor (Table 2). Importantly, the AIC decreased during the stepwise variable selection by 10 units, proving a better goodness of fit of the selection model and indicating its higher relevance in our set of data (Burnham and Anderson, 2003).

Rh-SDF1 $\alpha$ induces CXCR4-dependent tumour cell invasion. To date, only one study using a papillary thyroid carcinoma cell line demonstrated a potential role of the SDF1 $\alpha / C X C R 4$ axis in initiating tumour cell invasion and migration in thyroid carcinoma (Zhu et al, 2016). Since this functional relevance has not yet been reported for MTC, we took advantage of the MTC cell line TT, which expresses both chemokine receptors CXCR4 and CXCR7 as revealed by immunocytochemistry and western blot analyses (Figure 3A and $\mathrm{B}$ ). To investigate the impact of SDF1-driven invasiveness, we treated TT cells with increasing concentrations of rh-SDF $1 \alpha$ and measured the changes in invasive growth. RhSDF $1 \alpha$ induced a significant increase in the number of invading cells by a fold change of 1.5 as compared to cells treated with vehicle control $(P<0.01$; Figure $4 \mathrm{~A}$ and $\mathrm{B})$.

Next, we treated the cells with the well-described CXCR4 antagonists AMD3100 and WZ811. The incubation with the respective compounds markedly reduced the invasive capacity of the MTC cells. For both compounds the effect was more profound at higher concentrations suggesting a dose-dependent mechanism. The incubation with WZ811 at $100 \mathrm{nM}$ reduced the amount of invasive cells to 0.59 fold of the amount of control-treated cells $(P<0.05)$ while the incubation with $1 \mu \mathrm{M}$ caused a decrease in invasive cells by a fold change of $0.45(P<0.01$; Figure $4 \mathrm{~A}$ and $\mathrm{B})$. Similarly, the effect of AMD3100 became more obvious at $1 \mu \mathrm{M}$ than at $100 \mathrm{~nm}$ inducing a fold change of 0.53 of invading cells as opposed to 0.68 when compared to vehicle control-treated cells $(P<0.01$; Figure $4 \mathrm{~A}$ and $\mathrm{B})$. Interestingly, the inhibitory effect of the respective chemokine receptor antagonists persisted when the cells were co-incubated with rh-SDF1 $\alpha$ (data not shown).

Rh-SDF1 $\alpha$ induces invasiveness through cell cycle activation and EMT. To further elucidate the possible mechanisms behind the increase in invasiveness after incubation with rh-SDF1 $\alpha$ we performed cell cycle analyses using FACS technology. The 

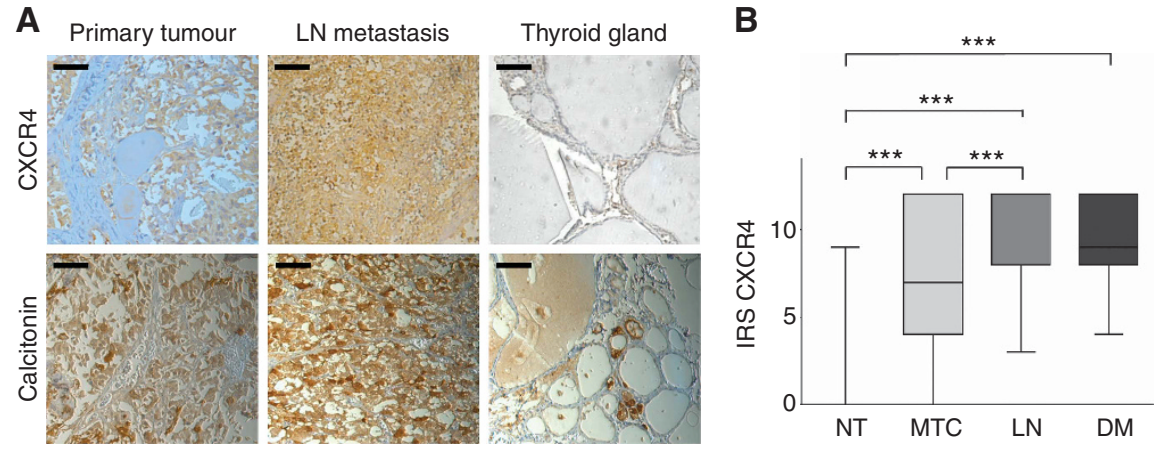

Figure 1. Expression of CXCR4 in MTC. (A) Representative tissue samples with immunohistochemical staining for CXCR4 and calcitonin in MTC (left), respective lymph node metastasis (middle) and non-neoplastic thyroid gland (right). All shown samples were classified as a strong expression for the given marker in accordance with the IRS. The bar at the top left corner indicates $50 \mu \mathrm{m}$. (B) Expression levels of CXCR4 in non-neoplastic thyroid tissue specimens and respective corresponding MTC, lymph node and distant metastases. Boxplots display the median IRS with the upper and lower quartile, as well as maximum and minimum for CXCR4. CXCR4 expression in the different tissue samples was compared between groups using the Wilcoxon matched-pairs signed rank test. Bars indicate the respective pairs. CXCR4=C-X-C chemokine receptor type 4; DM = distant metastases; IRS = immunoreactivity score; LN = lymph node metastases; MTC= medullary thyroid carcinoma; NT=non-neoplastic thyroid gland; $\star \star \star P<0.001$
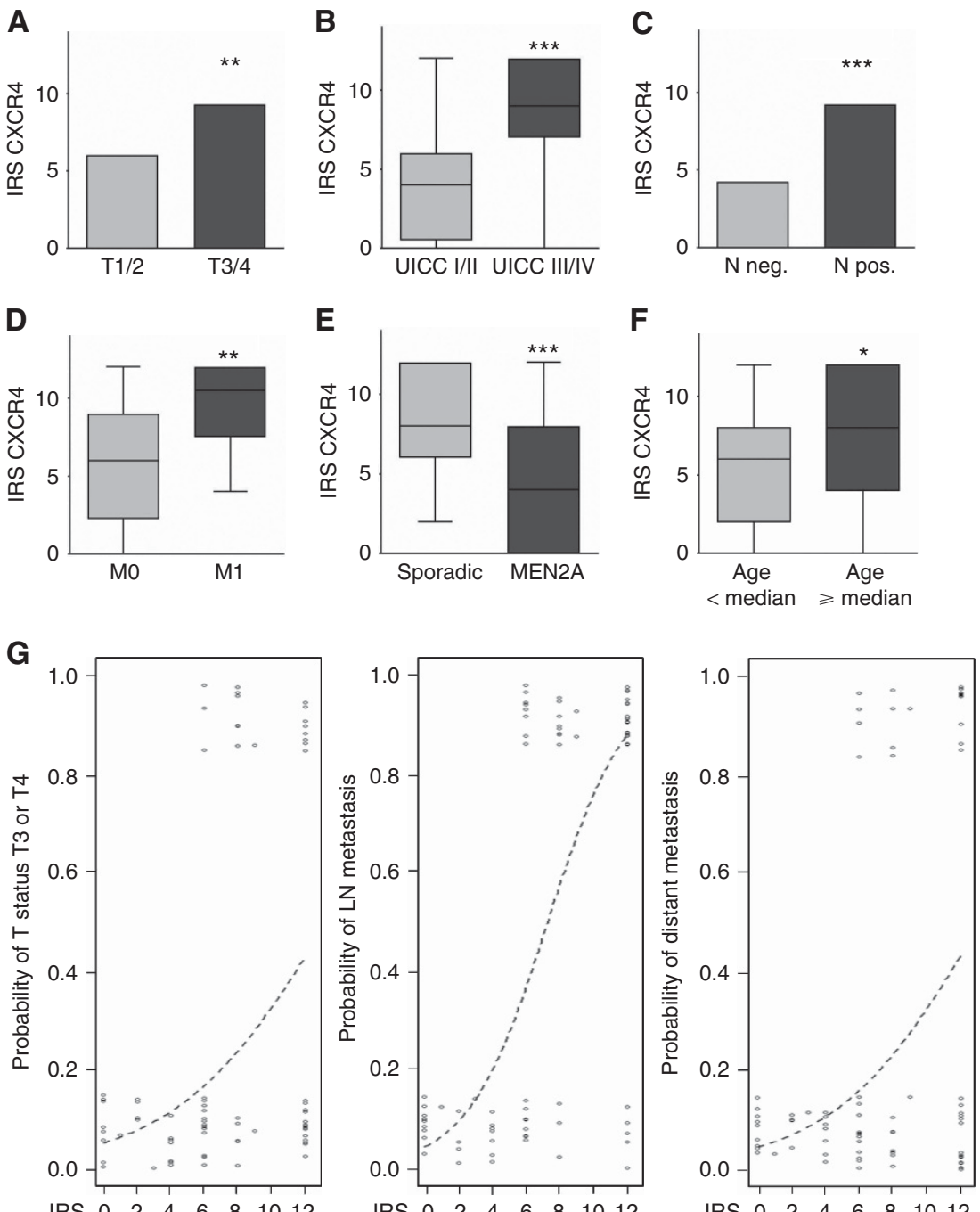

IRS $0 \begin{array}{llllllllll}0 & 4 & 6 & 8 & 10 & 12\end{array}$

IRS $0 \begin{array}{lllllll}0 & 2 & 6 & 8 & 10 & 12\end{array}$

IRS $0 \begin{array}{lllllllll} & 2 & 4 & 6 & 8 & 10 & 12\end{array}$

Figure 2. Association between CXCR4 expression and different clinicopathological parameters. (A-F) Boxplots display the median IRS with the upper and lower quartile, as well as maximum and minimum for CXCR4 in the primary tumour core grouped according to the given clinicopathological parameter. CXCR4 expression levels were compared using the non-parametric Mann-Whitney $U$ test. (G) Cox regression analyses demonstrate the correlation between increasing expression levels of CXCR4 and the likelihood of an advanced tumour stage or metastatic phenotype. CXCR4 = C-X-C chemokine receptor type 4; IRS =immunoreactivity score; $L N=$ lymph node; ${ }^{\star} P<0.05$; ${ }^{\star \star} P<0.01$; $\star \star \star P<0.001$ 
treatment with rh-SDF1 $\alpha$ resulted in a significant decrease of cells remaining in the G1 phase, while significantly more cells entered the $\mathrm{G} 2 / \mathrm{M}$ phase (Figure $4 \mathrm{C}$ ). Interestingly, these changes in cell cycle activation did not translate into an increase in cell proliferation (data not shown). Moreover, incubation of MTC cells with CXCR4 antagonists AMD3100 and WZ811 initiated no changes in cell cycle profiles or proliferation (data not shown).

Next, we investigated possible changes in mRNA expression levels of genes associated with EMT and tumour cell invasion. Whereas rh-SDF1 $\alpha$ induced no changes in the expression of SNAI1, the expression levels of BST2, FGF9 and Vimentin were significantly upregulated after rh-SDF1 $\alpha$ treatment $(P<0.01$; Figure 4D, Supplementary Table 3$)$. On the other hand, expression levels of E-cadherin were markedly reduced after incubation with rh-SDF1 $\alpha(P<0.05$; Figure 4D, Supplementary Table 3$)$.

\section{DISCUSSION}

Carcinomas of the thyroid gland are the most common endocrine malignancies in the world. They are responsible for

Table 2. Overall survival analysis

\begin{tabular}{|c|c|c|c|}
\hline Variables & HR & Cl (lower-upper 95\%) & $P$-value \\
\hline \multicolumn{4}{|c|}{ Univariate survival analysis } \\
\hline Age at first diagnosis & 3.740 & $1.477-9.469$ & 0.005 \\
\hline Sex & 1.893 & $0.749-4.785$ & 0.178 \\
\hline $\mathrm{T} 1 / 2$ vs T3/4 & 3.641 & $1.115-11.89$ & 0.032 \\
\hline $\mathrm{N}$ negative vs $\mathrm{N}$ positive & 4.773 & $1.879-12.13$ & 0.001 \\
\hline $\mathrm{M} 0$ vs M1 & 21.45 & $6.304-72.98$ & $<0.001$ \\
\hline Sporadic vs MEN2A & 6.289 & $2.193-18.03$ & $<0.001$ \\
\hline $\begin{array}{l}\text { Calcitonin basal blood } \\
\text { level }\end{array}$ & 3.688 & $0.856-15.89$ & 0.080 \\
\hline CXCR4 expression & 4.474 & $1.671-11.98$ & 0.003 \\
\hline \multicolumn{4}{|c|}{ Multivariate survival analysis } \\
\hline Age at first diagnosis & 3.1662 & $0.089-1.116$ & 0.074 \\
\hline Sex & 0.953 & $0.328-2.766$ & 0.930 \\
\hline $\mathrm{T} 1 / 2$ vs T3/4 & 1.074 & $0.360-3.202$ & 0.898 \\
\hline $\mathrm{N}$ negative vs $\mathrm{N}$ positive & 2.193 & $0.401-11.987$ & 0.365 \\
\hline $\mathrm{M} 0$ vs $\mathrm{M} 1$ & 2.219 & $0.558-8.823$ & 0.258 \\
\hline Sporadic vs MEN2A & 4.523 & $0.507-40.300$ & 0.176 \\
\hline $\begin{array}{l}\text { Calcitonin basal blood } \\
\text { level }\end{array}$ & 0.946 & $0.313-2.860$ & 0.922 \\
\hline CXCR4 expression & 1.045 & $0.867-1.261$ & 0.643 \\
\hline \multicolumn{4}{|c|}{ Multivariate survival analysis after stepwise variable selection } \\
\hline $\mathrm{M} 0$ vs M1 & 11.47 & $2.941-44.71$ & $<0.001$ \\
\hline \multicolumn{4}{|c|}{$\begin{array}{l}\text { Abbreviations: } \mathrm{Cl}=\text { confidence interval; } \mathrm{CXCR} 4=\mathrm{C}-\mathrm{X}-\mathrm{C} \text { chemokine receptor type } 4 ; \mathrm{HR}= \\
\text { hazard ratio; } \mathrm{MEN} 2 \mathrm{~A}=\text { multiple endocrine neoplasia type } 2 \mathrm{~A} \text {. The bold values are } \\
\text { statistically significant. }\end{array}$} \\
\hline
\end{tabular}

more patients' deaths than all other endocrine-associated malignancies combined (Ernani et al, 2016). Although surgery may be curative in the early stages of the disease, the majority of patients harbour distant metastases at the time of diagnosis $(\mathrm{Hu}$ et al, 2014). Locoregional and distant spread that occur during the early stages of the disease is not rarely the first clinical sign. Once the disease has spread the treatment options with curative intent are limited. In this regard, the discovery and new appreciation of the activating mutation of the RET protooncogene in hereditary and sporadic MTC patients has caused paramount changes in adjuvant therapeutic protocols. It has led to the replacement of mainly dacarbazin- and doxorubicin-based chemotherapeutic regimes by small molecule TKI (Lalami and Awada, 2011). However, after the initial euphoria had faded and the limited effects on progression-free survival became apparent, a new appraisal of the commonly altered signalling pathways in carcinogenesis has started to evolve (Licitra et al, 2010; Haddad, 2013; Hu et al, 2014).

CXCR4 has been linked to different tumour entities as a negative prognostic marker and important factor in carcinoma cell homing and subsequent metastasis (Chen et al, 2015; Krieg et al, 2015; Mego et al, 2016). Thus far, little is known about the CXCR4/ CXCR7/CXCL12 axis in MTC. To our knowledge, only one study has investigated the expression of CXCR4 and CXCR7 in MTC. In a study performed by Zhu et al only 10 MTC tissue specimens were immunohistochemically stained for CXCR4 and CXCR7 but no subsequent correlation with clinicopathological variables or functional analyses were performed (Zhu et al, 2016). Therefore, our study is the first that investigated the stage-dependent expression of CXCR4 and CXCR7 in MTC patients and further stratified their functional implications in vitro.

In our set of patients, CXCR4 was significantly higher expressed in MTC than in non-neoplastic thyroid tissue specimens. In addition, a high CXCR4 expression in the primary tumour was associated with a high probability of an advanced tumour stage, high UICC stage and metastatic phenotype. In the univariate analysis, elevated CXCR4 expression levels were also associated with a significantly worse prognosis. In the multivariate analysis however, only the presence of distant metastases proved to be an independent negative prognostic parameter. Taken together, these findings underscore the paramount importance of metastatic spread for the patients' outcome on the one hand and on the other draft a concept by which CXCR4 influences this powerful prognostic marker. So while metastatic disease determines the outcome, CXCR4 facilitates its formation.

CXCR7 on the other hand was almost not expressed in our MTC tissue probes, which is in line with the study by Zhu et al. There, only endothelial cells of adjacent blood vessels stained partially positive for CXCR7 (Zhu et al, 2016).
A

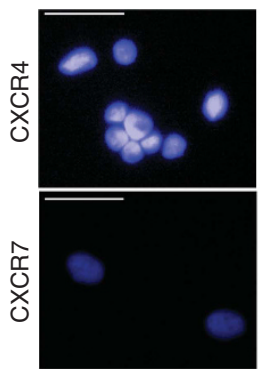

CXCR-AB

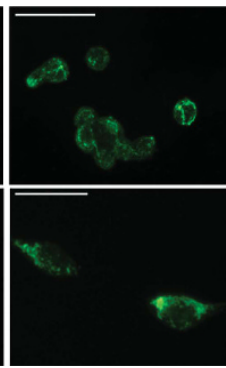

Overlay

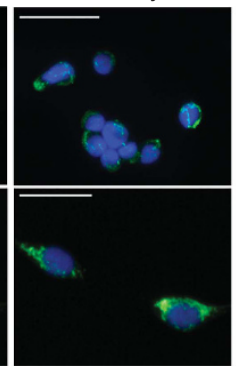

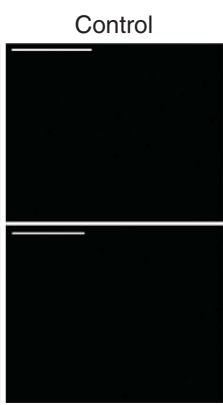

B

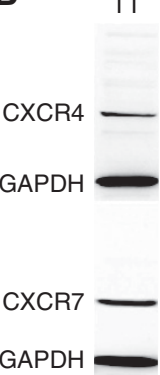

Figure 3. Expression levels of CXCR4 and CXCR7 in MTC cell line TT. (A) Immunocytochemical staining of CXCR4 and CXCR7 in MTC cell line TT using Alexa Fluor 488 as secondary antibody. DAPI was used for visualisation of the nucleus. Overlays demonstrate the composite images for both staining procedures. Antibody specificity was confirmed with isotype controls (control). Images were captured using a fluorescence microscope at $\times 400$ magnification. Bar at the top left corner indicates $50 \mu \mathrm{m}$. (B) Western blot analysis for both CXCR4 and CXCR7 in MTC cell line TT. GAPDH served as loading control. CXCR4/7 $=$ C-X-C chemokine receptor type 4/7. 

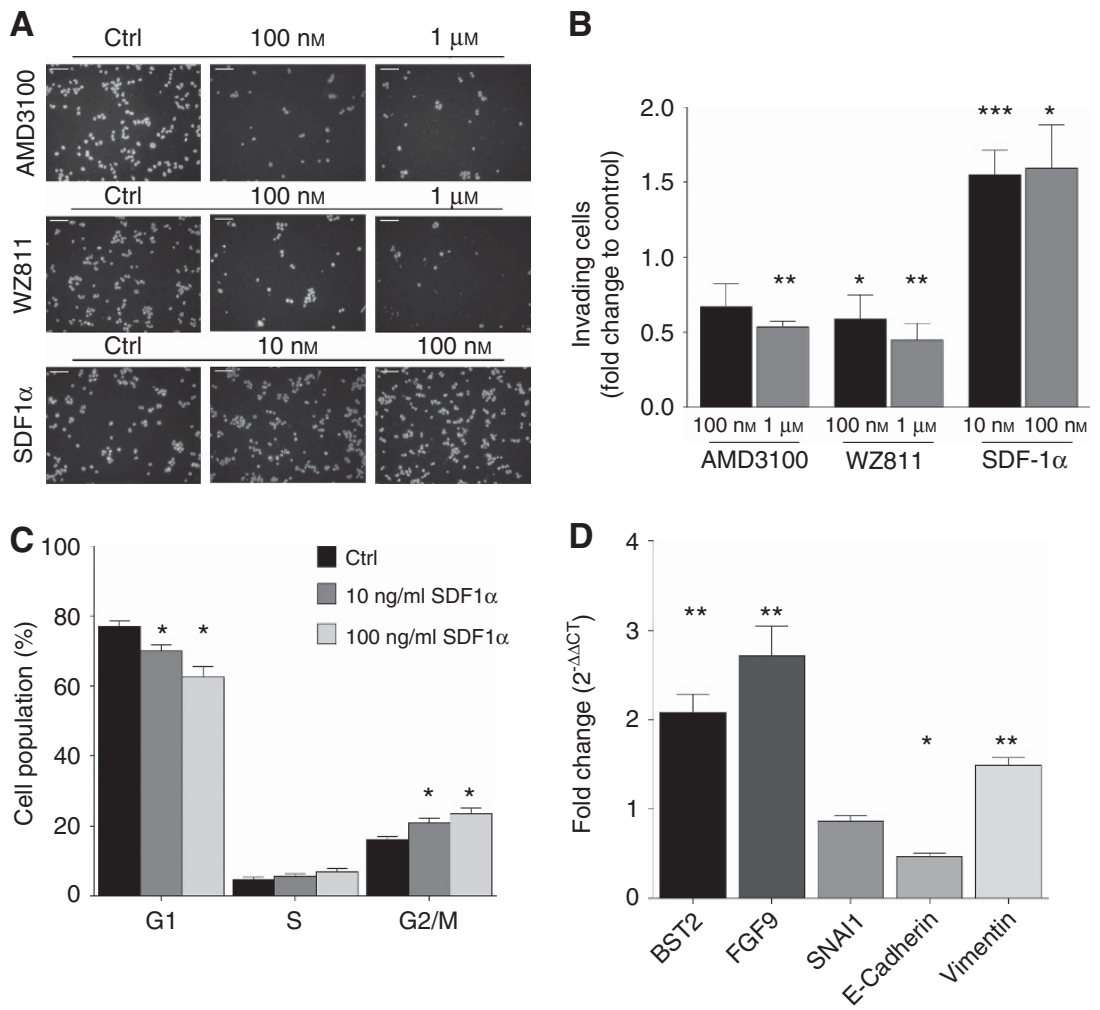

Figure 4. rh-SDF1 $\alpha$ induces tumour cell invasion, cell cycle activation and EMT. (A) Representative pictures of matrigel invasion membranes stained with DAPI for nuclear visualisation after treatment of human MTC cell line TT with CXCR4 antagonising compounds AMD3100 and WZ811 as well as chemokine receptor agonist rh-SDF1 $\alpha$. (B) The number of invading cells was estimated by counting cells in five visual fields of at least three separate membranes and illustrated as fold change to control. (C) After treatment with rh-SDF1 $\alpha$, cell cycle analyses were performed using PI staining and FACS. Cell populations are grouped according to the distinct cell cycle phase. (D) Changes in mRNA expression levels of EMTassociated genes were evaluated using qRT-PCR where GAPDH served as housekeeping gene. Fold changes were calculated using the $2^{-\triangle \triangle C T}$ method. All plots display the mean with s.e.m. Numerical data were analysed using the non-parametric Mann-Whitney $U$ test. CT values are displayed in Supplementary Table 3. Ctrl = vehicle control for the highest concentration; ${ }^{\star} P<0.05 ;{ }^{* \star} P<0.01 ;{ }^{\star \star \star} P<0.001$.

Considering the pivotal role of CXCR4 for tumour cell dissemination, the significantly higher expression of the chemokine receptor in lymph node metastases compared to the expression in the corresponding primary MTC specimens fits perfectly into our expanding knowledge of the CXCR4/CXCL12 axis in carcinoma. Mechanistically, the homeostatic microenvironment chemokine CXCL12 functions as a chemoattractant for CXCR4-expressing cells and modulates intracellular calcium flux, cell cycle activation and chemotaxis (Mego et al, 2016). This in turn leads to the initiation of different cell signalling pathways, which promote EMT, the forming of an invasive phenotype and tumour cell progression (Sobolik et al, 2014; Tu et al, 2016; Wu et al, 2016).

Our functional in vitro experiments demonstrated for both CXCR4 antagonising compounds AMD3100 and WZ811 a significant reduction in the number of invading cells. These observations are in line with the current literature where multiple studies have shown an anti-metastatic effect for both compounds. WZ811 exhibits a profound anti-tumourigenic potential in chronic lymphocytic leukaemia and negatively influences CD3-positive T-cell migration both in vitro and in vivo (Jung et al, 2014; Li et al, 2016). AMD3100 on the other hand is known to reduce the metastatic potential in small cell lung carcinoma (Taromi et al, 2016), breast cell carcinoma (Wendel et al, 2012) and oral squamous cell carcinoma (Uchida et al, 2007). Its predominant clinical application, however, is its capacity to mobilise haematopoietic stem cells from the bone marrow after transplantation for haematopoietic malignancies. Since cell migration in and out of the bone marrow follows opposite chemokine gradients, AMD3100 has proven itself a useful asset, especially in patients predicted to be poor stem cell mobilisers (Bilgin and de Greef, 2016; Danylesko et al, 2016).

The fact that a co-incubation with rh-SDF1 $\alpha$ could not overcome the inhibitory effect of the two CXCR4-specific antagonists in a cell model where both CXCR4 and CXCR7 were equally expressed, suggests that a functioning CXCR4 is mandatory for the CXCR4/ CXCR7/CXCL12 axis to fully evolve in MTC and cannot be entirely compensated by CXCR7 alone. Notably, one study by Kalatskaya et al even suggests AMD3100 as a ligand to CXCR7 with allosteric agonist properties, questioning not only its CXCR4-specificity but also its functionality (Kalatskaya et al, 2009). These observations support the hypothesis that CXCR7 functions as regulator to CXCR4 G protein signalling (Sierro et al, 2007; Sánchez-Martín et al, 2013). However, further functional experiments are warranted to fully elucidate the complex interaction between CXCR4, CXCR7 and their mutual ligand CXCL12.

The incubation of MTC cell line TT with rh-SDF1 $\alpha$ resulted in an activation of cell cycle and subsequent increase in the number of invading cells. Of note however, the increase in cell count in the G2/M phase did not translate into an increase in cell proliferation as investigated by BrdU colorimetric ELISA assay. The discrepancy may be attributed to the slow doubling time of the cell line and the fact that all in vitro studies were conducted in serum-starved culture medium. Owing to these circumstances, the respective lengths of the incubation periods of the MTC cell line were limited as the cultured cells succumbed to serum starvation and did not incorporate BrdU in a sufficient manner to corroborate the results from the FACS analyses.

The CXCR4/CXCR7/CXCL12 axis has been implicated with EMT in different tumour types, which in turn was held responsible for 
enhanced invasive growth and metastatic spread. As a marker for EMT, we investigated the changes in expression levels for Vimentin and E-cadherin following rh-SDF1 $\alpha$ treatment. We could demonstrate that the incubation of MTC cell line TT with rh-SDF1 $\alpha$ resulted in a significant upregulation of Vimentin while the expression of E-cadherin was markedly reduced, suggesting a cellular transition from epithelial to mesenchymal phenotype. Additionally, mRNA levels of EMT-associated transcriptional factors BST2 and FGF9 were markedly upregulated after rh-SDF1 $\alpha$ treatment.

BST2 is a known activator of NF- $\mathrm{BB}$, whose activation promotes tumour cell invasion and metastasis through EMT (Matsuda et al, 2003; Wu and Bonavida, 2009). In breast carcinoma BST2 has been identified as an independent marker for metastasis, its overexpression causing anchorage independent growth and facilitating invasiveness (Woodman et al, 2016). FGF9 on the other hand has been associated with EMT via the upregulation of vascular endothelial growth factor (Teishima et al, 2014) and its expression is linked to poor prognosis and a metastatic phenotype in different solid tumours (Ueng et al, 2010; Ohgino et al, 2014; Ren et al, 2016). The increased mRNA expression of these markers may be seen as an indicator of the underlying cellular machinery of the CXCR4/CXCR7/CXCL12-mediated metastatic push, but still requires further investigation to fully appreciate the molecular mechanics.

Since invasive growth and the subsequent formation of distant metastases are the primary deciding factors for fatal outcome, a better understanding of the molecular pathways of tumour cell dissemination and invasion is mandatory in developing new therapeutic strategies. Here, we propose the CXCR4/CXCR7/ CXCL12 axis as an important functional determinant in MTC tumour biology. With its distinct expression profile and strong association with disseminated disease, CXCR4 can be considered as a new and viable therapeutic target in advanced MTC. Especially its involvement in the induction of EMT offers new valuable insight into the oncogenesis of MTC and should provide encouragement for further preclinical studies.

\section{CONFLICT OF INTEREST}

The authors declare no conflict of interest.

\section{REFERENCES}

American Thyroid Association Guidelines Task ForceKloos RT, Eng C, Evans DB, Francis GL, Gagel RF, Gharib H, Moley JF, Pacini F, Ringel MD, Schlumberger M, Wells SA (2009) Medullary thyroid cancer: management guidelines of the American Thyroid Association. Thyroid 19: 565-612.

Balkwill F (2004) Cancer and the chemokine network. Nat Rev Cancer 4: 540-550.

Ball DW (2009) American Thyroid Association guidelines for management of medullary thyroid cancer: an adult endocrinology perspective. Thyroid 19: 547-550.

Bilgin YM, de Greef GE (2016) Plerixafor for stem cell mobilization: the current status. Curr Opin Hematol 23: 67-71.

Brierley JD, Gospodarowicz MK, Wittekind C (2016) TNM Classification of Malignant Tumours. John Wiley \& Sons.

Burger JA, Kipps TJ (2006) CXCR4: a key receptor in the crosstalk between tumor cells and their microenvironment. Blood 107: 1761-1767.

Burnham KP, Anderson DR (2003) Model Selection and Multimodel Inference. Springer Science \& Business Media.

Burns JM, Summers BC, Wang Y, Melikian A, Berahovich R, Miao Z, Penfold MET, Sunshine MJ, Littman DR, Kuo CJ, Wei K, McMaster BE, Wright K, Howard MC, Schall TJ (2006) A novel chemokine receptor for SDF-1 and I-TAC involved in cell survival, cell adhesion, and tumor development. J Exp Med 203: 2201-2213.
Chen N, Jiang X, Wang J, Wu T, Cheng B, Xia J (2015) CXCL12-CXCR4/ CXCR7 axis contributes to cell motilities of oral squamous cell carcinoma. Tumor Biology 37: 567-575.

Danylesko I, Sareli R, Varda-Bloom N, Yerushalmi R, Shem-Tov N, Shimoni A, Nagler A (2016) Plerixafor (Mozobil): a stem cell-mobilizing agent for transplantation in lymphoma patients predicted to be poor mobilisers - a pilot study. Acta Haematol 135: 29-36.

Donis-Keller H, Dou S, Chi D, Carlson KM, Toshima K, Lairmore TC, Howe JR, Moley JF, Goodfellow P, Wells SA (1993) Mutations in the RET proto-oncogene are associated with MEN 2A and FMTC. Hum Mol Genet 2: $851-856$.

Dralle H, Musholt TJ, Schabram J, Steinmüller T, Frilling A, Simon D, Goretzki PE, Niederle B, Scheuba C, Clerici T, Hermann M, Kußmann J, Lorenz K, Nies C, Schabram P, Trupka A, Zielke A, Karges W, Luster M, Schmid KW, Vordermark D, Schmoll H-J, Mühlenberg R, Schober O, Rimmele H, Machens A, German Societies of General and Visceral Surgery; Endocrinology; Nuclear Medicine; Pathology; Radiooncology; Oncological Hematology; and the German Thyroid Cancer Patient Support Organization Ohne Schilddrüse leben e.V (2013) German Association of Endocrine Surgeons practice guideline for the surgical management of malignant thyroid tumors. Langenbecks Arch Surg 398: 347-375.

Eng C, Clayton D, Schuffenecker I, Lenoir G, Cote G, Gagel RF, van Amstel HK, Lips CJ, Nishisho I, Takai SI, Marsh DJ, Robinson BG, Frank-Raue K, Raue F, Xue F, Noll WW, Romei C, Pacini F, Fink M, Niederle B, Zedenius J, Nordenskjöld M, Komminoth P, Hendy GN, Mulligan LM (1996) The relationship between specific RET proto-oncogene mutations and disease phenotype in multiple endocrine neoplasia type 2. International RET mutation consortium analysis. JAMA 276: $1575-1579$.

Ernani V, Kumar M, Chen AY, Owonikoko TK (2016) Systemic treatment and management approaches for medullary thyroid cancer. Cancer Treat Rev 50: 89-98.

Gebauer F, Tachezy M, Zander H, Izbicki JR, Kaifi J, Bockhorn M (2011) Prognostic impact of CXCR4 and CXCR7 expression in pancreatic adenocarcinoma. J Surg Res 165: 176.

Haddad RI (2013) New developments in thyroid cancer. J Natl Compr Canc Netw 11: 705-707.

Hu MI, Ying AK, Jimenez C (2014) Update on medullary thyroid cancer. Endocrinol Metab Clin North Am 43: 423-442.

Jung SH, Won KJ, Lee KP, Lee DH, Yu S, Lee D-Y, Seo E-H, Kang H, Park E-S, Kim H-J, Lee SH, Kim B (2014) DJ-1 protein regulates CD3 + T cell migration via overexpression of CXCR4 receptor. Atherosclerosis 235: 503-509.

Kalatskaya I, Berchiche YA, Gravel S, Limberg BJ, Rosenbaum JS, Heveker N (2009) AMD3100 is a CXCR7 ligand with allosteric agonist properties. Mol Pharmacol 75: 1240-1247.

Krieg A, Mersch S, Boeck I, Dizdar L, Weihe E, Hilal Z, Krausch M, Möhlendick B, Topp SA, Piekorz RP, Huckenbeck W, Stoecklein NH, Anlauf M, Knoefel WT (2014) New model for gastroenteropancreatic large-cell neuroendocrine carcinoma: establishment of two clinically relevant cell lines. PLoS One 9: e88713.

Krieg A, Riemer JC, Telan LA, Gabbert HE, Knoefel WT (2015) CXCR4 - a prognostic and clinicopathological biomarker for pancreatic ductal adenocarcinoma: a meta-analysis. PLoS One 10: e0130192.

Lagergren A, Månsson R, Zetterblad J, Smith E, Basta B, Bryder D, Akerblad P, Sigvardsson M (2007) The Cxcl12, periostin, and Ccl9 genes are direct targets for early B-cell factor in OP-9 stroma cells. J Biol Chem 282: 14454-14462.

Lalami Y, Awada A (2011) Recurrent thyroid cancer: a molecular-based therapeutic breakthrough. Curr Opin Oncol 23: 235-240.

Leboulleux SS, Baudin EE, Travagli J-PJ, Schlumberger MM (2004) Medullary thyroid carcinoma. Clin Endocrinol (Oxf) 61: 299-310.

Levoye A, Balabanian K, Baleux F, Bachelerie F, Lagane B (2009) CXCR7 heterodimerizes with CXCR4 and regulates CXCL12-mediated G protein signaling. Blood 113: 6085-6093.

Li SH, Dong WC, Fan L, Wang GS (2016) Suppression of chronic lymphocytic leukemia progression by CXCR4 inhibitor WZ811. Am J Transl Res 8: 3812-3821.

Licitra L, Locati LD, Greco A, Granata R, Bossi P (2010) Multikinase inhibitors in thyroid cancer. Eur J Cancer 46: 1012-1018.

Links TP, Verbeek HHG, Hofstra RMW, Plukker JTM (2015) Endocrine tumours: progressive metastatic medullary thyroid carcinoma: first- and second-line strategies. Eur J Endocrinol 172: R241-R251. 
Livak KJ, Schmittgen TD (2001) Analysis of relative gene expression data using real-time quantitative PCR and the 2(-Delta Delta C(T)) Method. Methods 25: 402-408.

Matsuda A, Suzuki Y, Honda G, Muramatsu S, Matsuzaki O, Nagano Y, Doi T, Shimotohno K, Harada T, Nishida E, Hayashi H, Sugano S (2003) Large-scale identification and characterization of human genes that activate NF-kappaB and MAPK signaling pathways. Oncogene 22: 3307-3318.

McShane LM, Altman DG, Sauerbrei W, Taube SE, Gion M, Clark GM, Statistics Subcommittee of the NCI-EORTC Working Group on Cancer Diagnostics (2005) Reporting recommendations for tumor marker prognostic studies (REMARK). J Natl Cancer Inst 97: $1180-1184$.

Mego M, Cholujova D, Minarik G, Sedlackova T, Gronesova P, Karaba M, Benca J, Cingelova S, Cierna Z, Manasova D, Pindak D, Sufliarsky J, Cristofanilli M, Reuben JM, Mardiak J (2016) CXCR4-SDF-1 interaction potentially mediates trafficking of circulating tumor cells in primary breast cancer. BMC Cancer 16: 127.

Müller A, Homey B, Soto H, Ge N, Catron D, Buchanan ME, McClanahan T, Murphy E, Yuan W, Wagner SN, Barrera JL, Mohar A, Verástegui E, Zlotnik A (2001) Involvement of chemokine receptors in breast cancer metastasis. Nature 410: 50-56.

Nicolson GL (1993) Paracrine and autocrine growth mechanisms in tumor metastasis to specific sites with particular emphasis on brain and lung metastasis. Cancer Metastasis Rev 12: 325-343.

Ohgino K, Soejima K, Yasuda H, Hayashi Y, Hamamoto J, Naoki K, Arai D, Ishioka K, Sato T, Terai H, Ikemura S, Yoda S, Tani T, Kuroda A, Betsuyaku T (2014) Expression of fibroblast growth factor 9 is associated with poor prognosis in patients with resected non-small cell lung cancer. Lung Cancer 83: 90-96.

Pozzobon T, Goldoni G, Viola A, Molon B (2016) CXCR4 signaling in health and disease. Immunol Lett 177: 6-15.

Remmele W, Hildebrand U, Hienz HA, Klein PJ, Vierbuchen M, Behnken LJ, Heicke B, Scheidt E (1986) Comparative histological, histochemical, immunohistochemical and biochemical studies on oestrogen receptors, lectin receptors, and Barr bodies in human breast cancer. Virchows Arch $A$ Pathol Anat Histopathol 409: 127-147.

Ren C, Chen H, Han C, Fu D, Wang F, Wang D, Ma L, Zhou L, Han D (2016) The anti-apoptotic and prognostic value of fibroblast growth factor 9 in gastric cancer. Oncotarget 7: 36655-36665.

Roland J, Murphy BJ, Ahr B, Robert-Hebmann V, Delauzun V, Nye KE, Devaux C, Biard-Piechaczyk M (2003) Role of the intracellular domains of CXCR4 in SDF-1-mediated signaling. Blood 101: 399-406.

Rosenkilde MM, Gerlach L-O, Jakobsen JS, Skerlj RT, Bridger GJ, Schwartz TW (2004) Molecular mechanism of AMD3100 antagonism in the CXCR4 receptor: transfer of binding site to the CXCR3 receptor. J Biol Chem 279: 3033-3041.

Scala S (2015) Molecular pathways: targeting the CXCR4-CXCL12 axis untapped potential in the tumor microenvironment. Clin Cancer Res 21: 4278-4285.

Schrevel M, Karim R, Haar ter NT, van der Burg SH, Trimbos JBMZ, Fleuren GJ, Gorter A, Jordanova ES (2012) CXCR7 expression is associated with disease-free and disease-specific survival in cervical cancer patients. Br J Cancer 106: 1520-1525.

Secchiero P, Celeghini C, Cutroneo G, Di Baldassarre A, Rana R, Zauli G (2000) Differential effects of stromal derived factor- $1 \alpha$ (SDF-1 $\alpha$ ) on early and late stages of human megakaryocytic development. Anat Rec 260: $141-147$.

Sierro F, Biben C, Martinez-Munoz L, Mellado M, Ransohoff RM, Li M, Woehl B, Leung H, Groom J, Batten M, Harvey RP, Martinez-A C, Mackay CR, Mackay F (2007) Disrupted cardiac development but normal hematopoiesis in mice deficient in the second CXCL12/SDF-1 receptor, CXCR7. Proc Natl Acad Sci USA 104: 14759-14764.

Sobolik T, Su Y-J, Wells S, Ayers GD, Cook RS, Richmond A (2014) CXCR4 drives the metastatic phenotype in breast cancer through induction of CXCR2 and activation of MEK and PI3K pathways. Mol Biol Cell 25: 566-582.

Strosberg JR (2013) Update on the management of unusual neuroendocrine tumors: pheochromocytoma and paraganglioma, medullary thyroid cancer and adrenocortical carcinoma. Semin Oncol 40: 120-133.
Sun X, Cheng G, Hao M, Zheng J, Zhou X, Zhang J, Taichman RS, Pienta KJ, Wang J (2010) CXCL12/CXCR4/CXCR7 chemokine axis and cancer progression. Cancer Metastasis Rev 29: 709-722.

Sánchez-Martín L, Sánchez-Mateos P, Cabañas C (2013) CXCR7 impact on CXCL12 biology and disease. Trends Mol Med 19: 12-22.

Tachibana K, Hirota S, Iizasa H, Yoshida H, Kawabata K, Kataoka Y, Kitamura Y, Matsushima K, Yoshida N, Nishikawa S, Kishimoto T, Nagasawa T (1998) The chemokine receptor CXCR4 is essential for vascularization of the gastrointestinal tract. Nature 393: 591-594.

Takahashi M (1995) Oncogenic activation of the ret protooncogene in thyroid cancer. Crit Rev Oncog 6: 35-46.

Taromi S, Kayser G, Catusse J, Elverfeldt von D, Reichardt W, Braun F, Weber WA, Zeiser R, Burger M (2016) CXCR4 antagonists suppress small cell lung cancer progression. Oncotarget 7: 85185-85195.

Teishima J, Yano S, Shoji K, Hayashi T, Goto K, Kitano H, Oka K, Nagamatsu H, Matsubara A (2014) Accumulation of FGF9 in prostate cancer correlates with epithelial-to-mesenchymal transition and induction of VEGF-A expression. Anticancer Res 34: 695-700.

Tu Z, Xie S, Xiong M, Liu Y, Yang X, Tembo KM, Huang J, Hu W, Huang X, Pan S, Liu P, Altaf E, Kang G, Xiong J, Zhang Q (2016) CXCR4 is involved in CD133-induced EMT in non-small cell lung cancer. Int J Oncol 50: 505-514.

Tuttle RM, Ball DW, Byrd D, Daniels GH, Dilawari RA, Doherty GM, Duh Q-Y, Ehya H, Farrar WB, Haddad RI, Kandeel F, Kloos RT, Kopp P, Lamonica DM, Loree TR, Lydiatt WM, McCaffrey J, Olson JA, Parks L, Ridge JA, Shah JP, Sherman SI, Sturgeon C, Waguespack SG, Wang TN, Wirth LJ (2010) Medullary carcinoma. J Natl Compr Canc Netw 8: 512-530.

Uchida D, Onoue T, Tomizuka Y, Begum NM, Miwa Y, Yoshida H, Sato M (2007) Involvement of an autocrine stromal cell derived factor-1/CXCR4 system on the distant metastasis of human oral squamous cell carcinoma. Mol Cancer Res 5: 685-694.

Ueng T-H, Chang Y-L, Tsai Y-Y, Su J-L, Chan P-K, Shih J-Y, Lee Y-C, Ma Y-C, Kuo M-L (2010) Potential roles of fibroblast growth factor-9 in the benzo(a)pyrene-induced invasion in vitro and the metastasis of human lung adenocarcinoma. Arch Toxicol 84: 651-660.

Wells SA, Pacini F, Robinson BG, Santoro M (2013) Multiple endocrine neoplasia type 2 and familial medullary thyroid carcinoma: an update. J Clin Endocrinol Metab 98: 3149-3164.

Wendel C, Hemping-Bovenkerk A, Krasnyanska J, Mees ST, Kochetkova M, Stoeppeler S, Haier J (2012) CXCR4/CXCL12 participate in extravasation of metastasizing breast cancer cells within the liver in a rat model. PLoS One 7: e30046.

Werner TA, Tamkan-Ölcek Y, Dizdar L, Riemer JC, Wolf A, Cupisti K, Verde PE, Knoefel WT, Krieg A (2016) Survivin and XIAP: two valuable biomarkers in medullary thyroid carcinoma. Br J Cancer 114: 427-434.

Woodman N, Pinder SE, Tajadura V, Le Bourhis X, Gillett C, Delannoy P, Burchell JM, Julien S (2016) Two E-selectin ligands, BST-2 and LGALS3BP, predict metastasis and poor survival of ER-negative breast cancer. Int J Oncol 49: 265-275.

Wright L, Maloney W, Yu X, Kindle L, Collinosdoby P, Osdoby P (2005) Stromal cell-derived factor- 1 binding to its chemokine receptor CXCR4 on precursor cells promotes the chemotactic recruitment, development and survival of human osteoclasts. Bone 36: 840-853.

Wu K, Bonavida B (2009) The activated NF-kappaB-Snail-RKIP circuitry in cancer regulates both the metastatic cascade and resistance to apoptosis by cytotoxic drugs. Crit Rev Immunol 29: 241-254.

Wu Y-C, Tang S-J, Sun G-H, Sun K-H (2016) CXCR7 mediates TGF $\beta 1$ promoted EMT and tumor-initiating features in lung cancer. Oncogene 35: 2123-2132.

Zhu X, Bai Q, Lu Y, Lu Y, Zhu L, Zhou X, Wu L (2016) Expression and function of CXCL12/CXCR4/CXCR7 in thyroid cancer. Int J Oncol 48: 2321-2329.

This work is published under the standard license to publish agreement. After 12 months the work will become freely available and the license terms will switch to a Creative Commons AttributionNonCommercial-Share Alike 4.0 Unported License. 